\title{
Research on the Data Collection and Management Model of College Students' Physical Fitness Test in Qingdao
}

\author{
Xiao-dong $\mathrm{Chu}^{1}$ \\ ${ }^{1}$ Qingdao University of Technology, Qingdao, China \\ Correspondence: Xiao-dong Chu. E-mail: xiaodongchu@126.com
}

Received: Janaury 18, 2017

Accepted: February 7, 2017

Online Published: April 19, 2018

doi:10.5539/ass.v14n5p29

URL: https://doi.org/10.5539/ass.v14n5p29

\begin{abstract}
In this article, some factors of the college students in Qingdao city are analyzed, such as basic situation, physical index scores, test scores, grades and the test of time and place, and personnel information, and the organization structure. The organization and arrangement of research and pilot testing staff, before the test and specific publicity notice the test group and the division of grades of reporting and summary, achievement upload and publicity, and supplementary work arrangements for some students, filing and management performance upload the test results of check and review work form are studied. To explore a suitable mode for the majority of college students physical health test data collection and management, to meet the standard of students' physique test data collection and management, achieve the aim that exploring a real, scientific, efficient and reasonable test data acquisition and management mode.
\end{abstract}

Keywords: data collection, management model, physical test

\section{Introduction}

In recent years, the physical condition of students has decreased year by year, which has attracted the attention of state leaders and relevant functional departments. Physical health management of college students in China is given priority to with experience in management (Chen \& Huang, 2007), the management and quality evaluation has not set up corresponding system, standards and requirements, management sense is short of system concept and the management process is weak, work interface lacks the clear regulation and management mechanism is underbelly, etc.

No matter what kind of College Students' physical health management mode, the first priority is that maintain the test data of the seriousness and accurate. Only a real data can reflect the true physical condition of college students, regulate college students' physical fitness test data collection and management, and explore a real, scientific, efficient and reasonable test data acquisition and management model. The real data is provided for the national education and sports departments could develop physical exercise guidance documents available, guide the sports courses in Colleges and universities set up a scientific arrangement, the real play to the educational function of physical education, after real data is provided (Chen \& Chen, 2010). Only on this way, it contributes to improve students' physique, carry forward the national principle and connotation of "Sunshine Sports" activities, truly achieve the aim that exercise every day. Fifty years of health, a happy life".

\section{Research Method}

\subsection{Subject Investigated}

Classes of 2015 freshmen in Qingdao University of Science and Technology are the subject investigated.

\subsection{Research Contents}

The basic situation of the students, single index scores, test scores, grades, time and place of the test, and personnel information. And the test organizational structure, organization and arrangement of the staff, the test publicity notice, the test specific packet and the division, the result of reporting and summary, achievement upload and publicity, and supplementary work arrangements for some students, schools and departments to formulate relevant supporting documents, filing and management scores after uploading, check and review of test scores (Du \& Zhu, 2010). 


\subsection{Objectives of the Study}

According to the 2013 "national student physical health standards" (hereinafter referred to as the "standard" test and report the work of the notice of the new requirements of the document, real, scientific, efficient and reasonable arrangements for the test work. To study and explore a data acquisition and management model suitable for most college students' physical health (Wu \& Cai, 2008).

\section{Discussion and Analysis}

\subsection{The Key Problems Plan to Be Solved}

Test object of the test work do not understand, do not pay attention to the problem.

Most of the students are not clear the content and purpose of the college students' physical fitness test. Some students are not clear the project of the test. The reason may be that although the college students' physique monitoring results an important indicator of the students' comprehensive quality evaluation and academic proficiency test and student appraising, but the decline in the actual operation process to implement. Some students take college students' physical fitness test as a burden.

\subsubsection{Test Workload Is Huge, Time Is Tight}

Base on the 2013 "standard" document requirements, the test items include 9 men and women, respectively. 2013 internal students of Qingdao University of Science and Technology as an example: a total of 27543 students, the total number of tests for 247887 passengers. The time of testing routine from the beginning of September to December 31. The basic situation of the students, supplementary work of some students, filing and management achievement after uploading, check and review of test scores.

\subsubsection{The Problem of Multi Evaluation, Long Process and Inaccurate Data}

Due to the test items for men and women are 9, respectively. So different projects will be arranged in different locations, different time, different test methods and staff. The data error will be produced in the process of concentration from one point to one surface.

\subsubsection{The Test Results Could Not Be Applied In the Management of Students}

The results of physical health test for schools lack the path of feedback. Teachers, students. The result of college students physique monitoring could not be view as important indicators of the students' comprehensive quality evaluation, academic proficiency test and student appraising.

\subsection{Program Design and Problem Solving Methods}

\subsubsection{Program Design}

2014 freshmen as a study case, after the first semester freshmen military training ended, the university physical education time, a class as a unit according to height, weight, vital capacity, eyesight, standing long jump, sit and reach, 50 meters, pull-up (male), sit ups (female), 1000 meters (male, 800) $\mathrm{m}$ (female) in order to test. Taking into account the physical condition of the students, the test takes about 5 weeks to complete. The organization and supervision of the test work is mainly composed of physical education teachers in the class, the director of monitoring the health center of college students is responsible for the overall coordination and organization of the test work. Summary and upload of the results by the center for monitoring the health of college students to arrange some of the backbone teachers to use 2 weeks to complete.

The second semester of college physical education class time, the class as a unit in accordance with the sit and reach, pull-up (male), sit ups (female), 1000 meters (male), 800 meters (female) in order to test. The test can be carried out in the second half of the second semester. The organization and supervision of the test work is mainly composed of physical education teachers in the class, the director of monitoring the health center of college students is responsible for the overall coordination and organization of the test work.

The third semester of college physical education class, the class as a unit test according to the height, weight, vital capacity, eyesight, standing long jump, 50 meters of order. The organization and supervision of the test work is mainly composed of physical education teachers in the class, the director of monitoring the health center of college students is responsible for the overall coordination and organization of the test work. Summary of the results and upload by the center for monitoring the health of college students to arrange some of the backbone teachers to use 2 weeks to complete.

The fourth semester of the second semester the university physical education time, taking a class as a unit in accordance with the sit and reach, pull-up (male), sit ups (female), 1000 meters (male), 800 meters (female) in order to test. The test can be carried out in the second half of the second semester. The organization and 
supervision of the test work is mainly composed of physical education teachers in the class, the director of monitoring the health center of college students is responsible for the overall coordination and organization of the test work.

The fifth semester of the weekend's spare time for testing, the school and class as a unit test according to the height, weight, vital capacity, eyesight, standing long jump, 50 meters of order. The director of monitoring the health center of college students is responsible for the overall coordination and organization of the test work. Summary and upload of the results by the center for monitoring the health of college students to arrange some of the backbone teachers to use 2 weeks to complete.

The seventh semester of the weekend's spare time for testing, the school and class as a unit according to height, weight, vital capacity, eyesight, standing long jump, sit and reach, 50 meters, pull-up (male), sit ups (female), 1000 meters (male), 800 meters (female) in order to test. Taking into account the physical condition of the students, the test takes about 5 weeks to complete. The organization and supervision of the test work is mainly composed of physical education teachers in the class, the director of monitoring the health center of college students is responsible for the overall coordination and organization of the test work. Summary and upload of the results by the center for monitoring the health of college students to arrange some of the backbone teachers to use 2 weeks to complete.

\subsubsection{Solution of the Problem}

\subsubsection{The Construction of College Students' Health Management Network Service Platform}

At present, there are a large number of students in Colleges and universities, and the college students' physical health managers are seriously inadequate. The establishment of College Students' physical health management network service platform can be more convenient to meet the health needs of many students, improve the efficiency of physical health management. The network management platform of physical health management can realize the function of information release, appointment management, the inquiry and health education of students' physical fitness. These functions can be used to come true the organic unity, which includes the contents of College Students' physical health management, the arrangement of test work, the evaluation of physical health, consultation and guidance, health intervention and other aspects. The network software system of the school and the management department should be able to share with each other, so that the health of the students can be effectively monitored both on the macro and micro level.

\subsubsection{Implementation of Monitoring Results Publicity System}

The results of the students' physical health test are published in campus according to the grade, class, gender and other categories.

\subsubsection{To Establish a System for Testing Result Application}

The school should make the" National Students Physical health standard card". This card is mainly used by students and include personal information and photos. Physical health test scores and evaluation levels of each student are recorded regularly. These will be regarded as an important index and the content of the students' comprehensive quality evaluation and academic proficiency test, and an important basis for college student appraise, graduation examination and entering a higher school.

Improve the data review system. The higher education administrative department will responsible for the supervision of the school to carry out a comprehensive test work and timely reporting of test data, register the national student physical health standard data management system, review report to the integrity, authenticity and validity of the test data, in accordance with the user management authority management system set up. After verification, the test date will be submitted.

\subsubsection{Establish a Data Review System}

Basis on the test date report of the education department each year to entrust the third party agencies in the country, considering the school type, gender, grade, regional distribution and other factors, the selected department advisor will be randomly selected a certain percentage of the sample, for on-site testing the test data and work of the spot checks. The date of on-site testing data will be compared with school report test data.

\section{Conclusion}

The data acquisition and management model of hierarchical test should be regular. The division of labor at all levels should be clear, to reduce workload at all levels, to improve work efficiency.

The students' physique health management network service platform should be constructed. This will 
conveniently meet many student health service demand, improve the working efficiency of the physique health management.

The data review system should be established, to improve the accuracy of test data, to reduce errors.

\section{References}

Chen J. F., \& Chen, M. (2010). Discussion on the construction of physical education teaching quality management system in Colleges and Universities Based on ISO9000 standard quality management principles. Journal of Shandong Institute of Physical Education and Sports, 26(8), 87-89.

Chen, J. S., \& Huang, J. S. (2007). Health Manager. Beijing: China Union Medical University Press.

Du, X. A., \& Zhu, B. (2010). Follow up service management mode and application of College Students' physical health test. Journal of Chengdu Sport University, (8), 91-94.

Wu, Z. J., \& Cai, X. B. (2008). Investigation and Research on the development of students' physical health management in Colleges and Universities. Journal of Nanjing Sport Institute, 22(1), 102-106.

\section{Copyrights}

Copyright for this article is retained by the author(s), with first publication rights granted to the journal.

This is an open-access article distributed under the terms and conditions of the Creative Commons Attribution license (http://creativecommons.org/licenses/by/4.0/). 